\title{
Estimativa do tempo de produção de chorume em aterro controlado por meio de medidas de resistividade elétrica
}

\author{
César Augusto Moreira', Antonio Celso de Oliveira Braga' ${ }^{1}$ \& \\ Marco Antonio Fontoura Hansen ${ }^{2}$
}

\begin{abstract}
Resumo Aterro é uma obra de engenharia que objetiva acomodar resíduos no menor espaço possível no solo, com danos mínimos ao ambiente e à saúde pública. Uma das formas construtivas de um aterro controlado é a escavação de valas com dimensões apropriadas, para disposição de resíduos sólidos sem compactação ou impermeabilização. Efluentes líquidos gerados por volumes de resíduos semelhantes, dispostos em valas com idades distintas de fechamento, devem resultar em alterações físicas e químicas correlacionáveis ao tempo de residência dos materiais. Com base nesta hipótese, foram realizadas medidas de resistividade elétrica por meio do método geofísico da Eletrorresistividade, sobre valas de resíduos fechadas anualmente entre 12/2001 e 12/2007, localizadas no aterro controlado do município de Cordeirópolis (SP). O chorume é um efluente líquido gerado pela decomposição de matéria orgânica e caracterizado pelo elevado conteúdo de sais dissolvidos, cuja interação com ambiente geológico resulta em alterações em termos de resistividade elétrica passíveis de detecção pelo instrumental geofísico. Os resultados sugerem uma redução da resistividade por percolação de chorume produzido em valas recentes e aumento progressivo da resistividade para valas mais antigas. A análise estatística comparativa com valores de referência para a área sugere idades de término da produção e percolação de chorume para solo e rocha abaixo das valas.
\end{abstract}

Palavras-chave: monitoramento, SEV, chorume, lixo.

\begin{abstract}
Abstratc Time estimative of the leachate production in control landfill by electrical resistivity measuring. Landfill is an engineering work that aims at to accommodate residues in the smallest possible space in the soil, with minimum damages to the environment and the public health. One in the constructive forms of a controlled landfill is the excavation of ditches with appropriate dimensions, for disposition of solid residues without compactation or impermeabilization. Liquid effluents generated for similar volumes of residues, disposed in ditches with ages different from closing, it should result in physical and chemical alterations you correlated at the time of residence materials. With base in this hypothesis, measures of electric resistivity were accomplished through the of Eletrical Resistivity geophysical method, on residues ditches closed annually between 12/2001 and 12/2007, localized in control landfill of the Cordeirópolis city (SP). The leachate is a liquid effluent generated by the decomposition of organic matter and characterized by high content in total dissolved solids, whose interaction with geological environment results in alterations in terms of electrical resistivity susceptible to detection for the geophysical instrumental. The results suggest a resistivity reduction for leachate percolation produced for ditches recently and increase progressive of the resistivity for older ditches. The statistical comparative analysis with reference values for the area suggests ages of the finish production and percolation leachate for soil and rock below the ditches.
\end{abstract}

Keywords: monitoring, VES, leachate, waste.

INTRODUÇÃO A intensificação do convívio em cidades e a padronização das formas de fabricação e consumo são traduzidas no expressivo aumento da produção de resíduos sólidos, e constitui um grande desafio para os gestores públicos. As formas atualmente utilizadas para disposição final de resíduos sólidos podem ser resumidas em: incineração, compostagem, disposição em lixões e aterros tipo sanitário ou controlado.

Os resíduos sólidos originados da rotina diária das residências são constituídos por restos orgânicos de alimentos, produtos deteriorados, jornais e revistas, garrafas, embalagens em geral, papel higiênico, fraldas descartáveis, dentre uma grande diversidade de outros itens. Pode conter ainda resíduos com diversos graus de toxicidade, como tintas, solventes, pigmentos, vernizes, pesticidas, inseticidas, repelentes, herbicidas, óleos lubrificantes, fluidos de freio e transmissão, baterias, pilhas, frascos de aerossóis, lâmpadas fluorescentes, dentre outros.

Aterro é uma obra de engenharia que objetiva acomodar resíduos no menor espaço possível, com danos mínimos ao ambiente e à saúde pública. Essa 
técnica consiste na compactação de resíduos no solo, na forma de camadas que são periodicamente cobertas com solo ou outro material inerte (ABNT 1989).

Atualmente os aterros são alvos de críticas por não compreenderem reciclagem, necessitarem de grandes áreas para implantação, operação sujeita a condições climáticas favoráveis, além do consequente risco de contaminação do solo e água subterrânea pela disposição dos materiais diretamente sobre o solo.

Contudo, os aterros são a principal forma atualmente empregada na disposição final de resíduos sólidos urbanos, bem como os provenientes de outras formas de destinação, como coleta seletiva, compostagem e incineradores.

O gerenciamento de aterros compreende uma série de procedimentos, como:

- Implantação de políticas de redução do volume de material destinado, pela implantação de programas de coleta seletiva e compostagem.

- Rígido controle operacional do material destinado, com minimização do período entre a chegada e destino final; cobertura do resíduo por solo ou material inerte e de baixa permeabilidade.

- Monitoramento da área de forma direta e indireta, para avaliação da área impactada pelo fluxo de lixiviado e variações diante das sazonalidades ambientais.

$\mathrm{O}$ uso de métodos geofísicos para caracterização e monitoramento de áreas contaminadas ou potencialmente contaminadas, possibilita a determinação de áreas em subsuperfície que eventualmente apresentem alterações em determinados parâmetros físicos devido à presença de contaminantes.

Diversos trabalhos demonstram a possibilidade de mapeamento de áreas contaminadas por meio de geofísica aplicada devido à relação entre queda na resistência elétrica no ambiente geológico em presença de chorume ou lixiviado (Moura \& Malagutti Filho 2003, Mondelli et al. 2007, Moreira et al. 2009, Lago et al. 2009, Santos et al. 2009).

O trabalho de Bell \& Jermy (1995), dentre muitos outros, descreve a relação direta entre decréscimo de sólidos totais dissolvidos (STD) e da condutividade elétrica com o distanciamento do aterro. A geração de chorume e suas características químicas, físicas e microbiológicas, estão relacionadas aos processos de decomposição de matéria orgânica presentes nos resíduos sólidos (Christensen et al. 1994).

Nesta pesquisa foram selecionadas diversas valas de resíduos sólidos, com idades distintas de fechamento, contidas em um aterro controlado localizado em Cordeirópolis (SP). Cada vala selecionada possui volume semelhante de resíduos contidos e provenientes da mesma fonte geradora, ou seja, quantidade semelhante de resíduos orgânicos passíveis de decomposição.

A ação de processos de atenuação natural em aterros tende ao completo consumo da matéria orgânica contida (Birks \& Eyles 1997). A partir deste momento ocorre o término na geração de chorume, com consequente retorno aos valores naturais de resistividade elétrica do ambiente geológico.
Baseado neste pressuposto, o presente estudo apresenta e discute os resultados de aplicação de sondagens elétricas verticais (SEVs) sobre tais valas, com o objetivo de realizar medidas de resistividade elétrica para a camada de resíduos e camadas de solo e rocha sotopostas. A análise estatística de um parâmetro físico diretamente relacionado à presença e teor de chorume no ambiente geológico, obtido em valas com diversas idades de fechamento, permite estimar o tempo requerido para consumo de matéria orgânica e término na produção de chorume.

\section{COMPORTAMENTO FISICO-QUÍMICO DO CONTAMINANTE NO AMBIENTE GEOLÓGI-} CO O chorume pode conter substâncias tóxicas e perigosas sob a forma sólida, líquida ou gasosa e pode apresentar elevadas concentrações de cloreto, ferro e zinco. Os elementos com elevada mobilidade iônica geralmente apresentam altas concentrações em comparação aos elementos de baixa mobilidade iônica (Bagchi 1987).

A composição do material livixiado depende do tipo e da idade do resíduo depositado no aterro, taxa de infiltração de água e pH. Entretanto, a quantidade de gás e material livixiado produzido pode ser afetada pela profundidade de disposição do material, condições climáticas regionais, variações do nível freático, espessura do material de recobrimento e controle de entrada e saída de líquidos da área (Farquhar 1989). É esperado que nas partes rasas do material ocorra rápida decomposição aeróbica enquanto que no corpo de resíduos em profundidade ocorra somente a decomposição parcial sob condições anaeróbicas.

O transporte de chorume através do aterro é lento, inconstante, não uniforme e descontínuo em muitos casos, dependendo do grau de compactação do material e de mudanças sazonais no suprimento de água do sistema (Fang 1995).

Ao cruzar a base do aterro, íons metálicos em solução podem ser removidos por troca iônica, sorção ou precipitação direta no substrato, especialmente quando argiloso. Os elementos orgânicos lixiviados que adentram no sistema aquífero anaeróbico - base do nível freático, são lentamente biodegradados, gerando ácidos que podem reagir com os materiais que estruturam o aquífero, com consequentes alterações no fluxo geoquímico do nível (Bennett \& Siegel 1987).

A quantidade de água subterrânea contaminada, resultante da invasão de material lixiviado, depende das condições hidrogeológicas da área e da capacidade de atenuação do substrato. Este processo pode ser efetivo por diluição e dispersão em aquíferos de alta permeabilidade e com elevada condutividade hidráulica. No caso de aquíferos menos permeáveis ou de baixa condutividade hidráulica, a contaminação carregada com sais inorgânicos pode provocar mineralizações no aquífero (Meju 2000).

Abaixo do nível freático, a mistura de chorume com a água subterrânea e reações com o material do 
substrato, forma uma pluma eletricamente condutiva. Além dos limites da pluma, a quantidade de STD e a condutividade elétrica apresentam valores intrínsecos aos do ambiente natural (Bennett \& Siegel 1987).

ÁREA DE ESTUDOS O aterro estudado está localizado no km 4,5 da rodovia Cássio Freitas Levy, município de Cordeirópolis, Estado de São Paulo, Brasil (Fig. 1). O município possui aproximadamente 17.000 habitantes e economia baseada na produção de revestimentos cerâmicos e cultivo de cana-de-açúcar. A produção diária de resíduos sólidos domiciliares é da ordem de $6,0 \mathrm{~m}^{3}$.

A prefeitura municipal de Cordeirópólis aderiu ao projeto Aterro Sanitário em Valas em 2000, uma das ações promovidas pela Secretaria de Estado do Meio Ambiente em atendimento à Política Nacional de Meio Ambiente, instituída pela Lei n 6938 de 1981.

No âmbito dos resíduos sólidos que devem ter tratamentos e destinos específicos, classificados genericamente em industriais, domésticos e serviços de saúde, são destacados os resíduos gerados pelas residências e comércio em geral, cuja destinação final apresenta índices de qualidade abaixo da média (IQR de $2004=6,8$ ), para cidades com até 100.000 habitantes, segundo os Inventários Estaduais de Resíduos Sólidos Domiciliares (CETESB 2005), que no Estado de São Paulo somam 578 municípios alvos deste projeto.

A técnica consiste no preenchimento de valas escavadas com dimensões apropriadas, onde os resíduos são depositados sem compactação e posteriormente cobertos com terra (SMA 2005). O confinamento dos resíduos sem compactação impede o aproveitamento integral da área aterrada, algo que torna esse procedimento inadequado para a maioria das comunidades com produção de resíduos superior a $10 \mathrm{t} / \mathrm{dia}$.

Desta forma, área de estudos é um aterro controlado do tipo vala, para deposição apenas de resíduos sólidos domiciliares. O sistema de operação consiste em valas com 5,0 $\mathrm{m}$ de profundidade, $4,0 \mathrm{~m}$ de largura e $80,0 \mathrm{~m}$ de comprimento, para deposição de resíduos

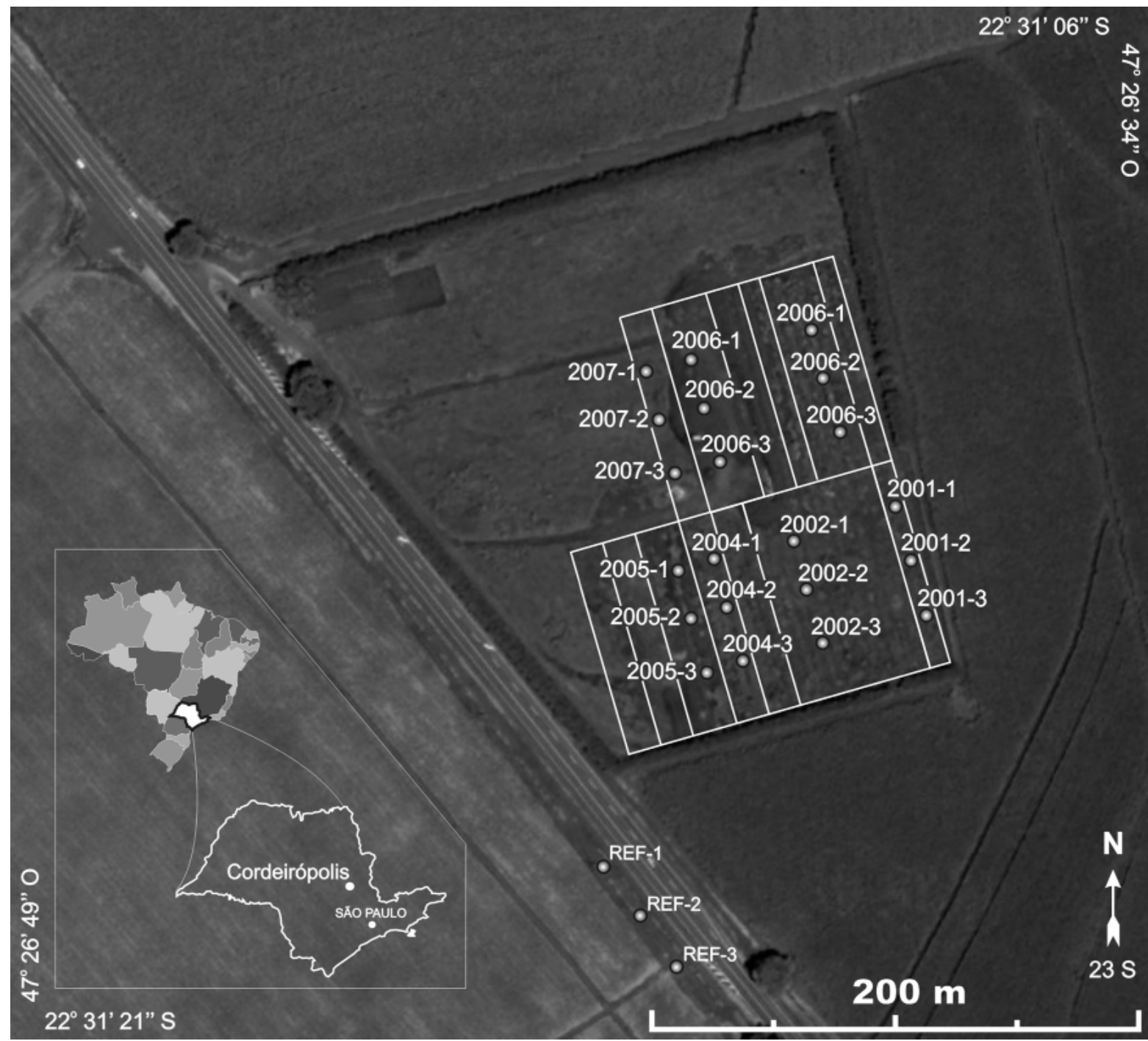

Figura 1 - Área de estudos, com a posição central das sondagens elétricas verticais referenciadas ao ano de fechamento da vala de resíduos investigada. 
diretamente sobre o solo e subsequente cobertura com uma camada de 1,0 m de solo. Apresenta $48.400 \mathrm{~m}^{2} \mathrm{de}$ área disponível, com início das atividades em 11/2001 e vida útil prevista para 20 anos (Fig. 2).

A topografia da área é bastante plana, com declive médio de $0,5 \%$ sentido Sudeste e altitude entre 660 e 659 $\mathrm{m}$. O aterro é cercado por fazendas de cultivo de cana-de-açúcar.

O substrato é constituído por solo argiloso com cerca de $10 \mathrm{~m}$ de espessura, sotoposto por uma soleira de diabásio com $10 \mathrm{~m}$ de espessura. Abaixo deste ocorrem arenitos finos e siltitos pertencentes à Formação Tatuí. O nível freático local está localizado a $50 \mathrm{~m}$ de profundidade, próximo ao contato basal da Formação Tatuí, determinado por meio de sondagens elétricas profundas e descrições de poços tubulares profundos localizados nas proximidades de área.

As valas selecionadas para estudo apresentam dimensões semelhantes e receberam volumes semelhantes de resíduos sólidos domiciliares. Durante o período compreendido entre o fechamento da primeira e da última vala selecionada, ou seja, entre 12/2001 e $12 / 2007$, ocorreu um pequeno aumento no volume de resíduos gerados pelos munícipes. Entretanto, devido à preservação dos hábitos de consumo da população, é presumível que o volume de resíduos orgânicos tenha sido proporcionalmente constante.

Foram realizadas medidas de condutividade hidráulica saturada (Ksat), por meio de permeâmetro do tipo Ghelph em diversos pontos ao redor do aterro, com medidas que variam de $8,08 \times 10^{-5} \mathrm{~cm} / \mathrm{s}$ a $1,04 \times 10^{-4}$ $\mathrm{cm} / \mathrm{s}$, para profundidades de $30 \mathrm{~cm}$.

A partir de amostras de solo coletadas em exposições ao longo da rodovia de acesso ao aterro, foram realizados ensaios de peneiramento e análise granulométrica, apresentados em termos de porcentagem para quatro horizontes de solo descritos.

Os dados revelam a predominância da fração argila na composição do solo, que constitui, em média, $70 \%$ do intervalo entre 0 a $5 \mathrm{~m}$ de profundidade e pela média de $18 \%$ da fração silte. Entre 5 e $10 \mathrm{~m}$ também predomina a fração argila com média de $80 \%$, seguida pela fração areia fina, com 7\% em média (Fig. 3).

MATERIAIS E MÉTODOS Foi adotada a técnica de Sondagem Elétrica Vertical para aquisição de dados
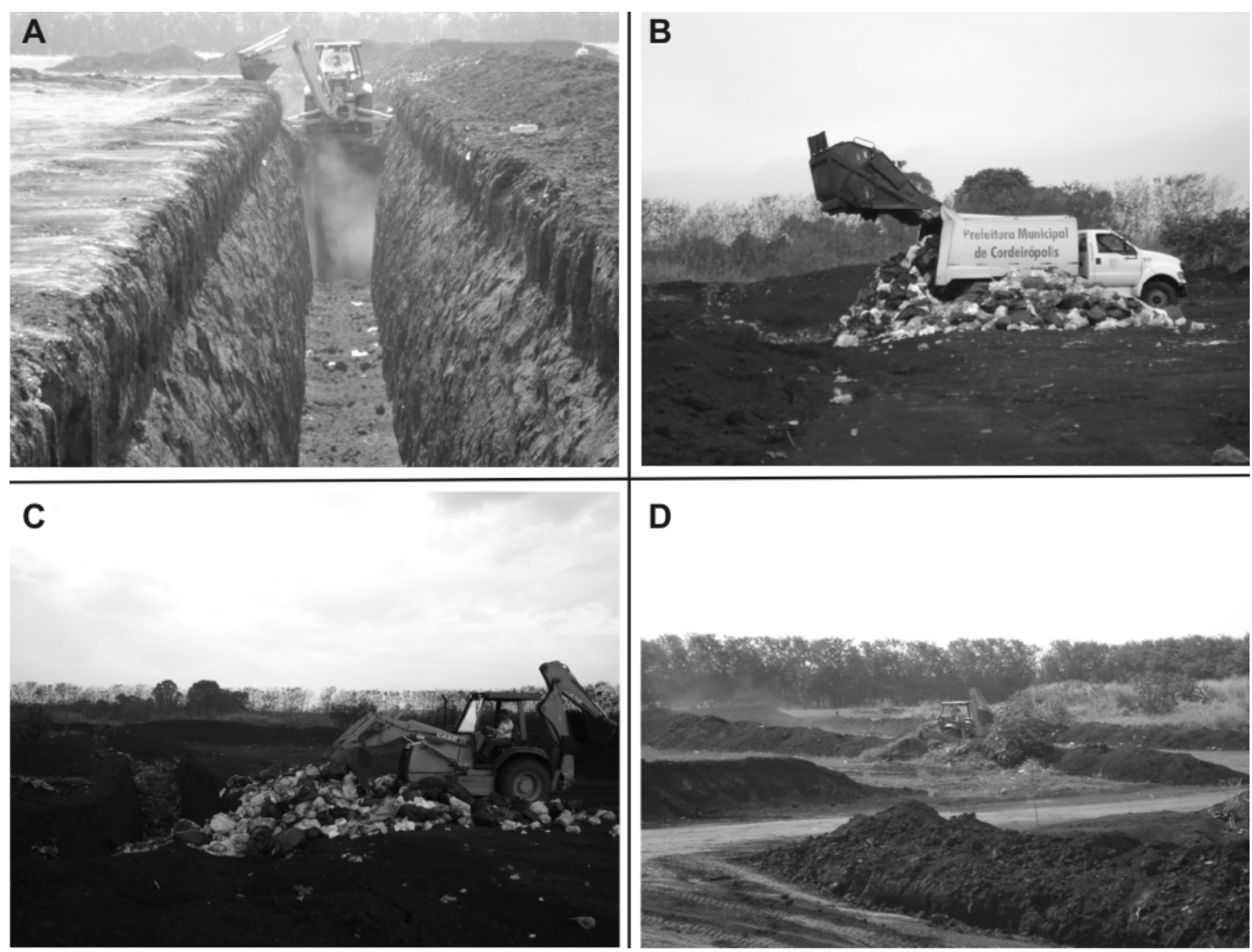

D

Figura 2 - Etapas de operação. A) Abertura de vala. B) Descarga de resíduos. C) Lançamento e cobertura dos residuos. D) Valas finalizadas. 


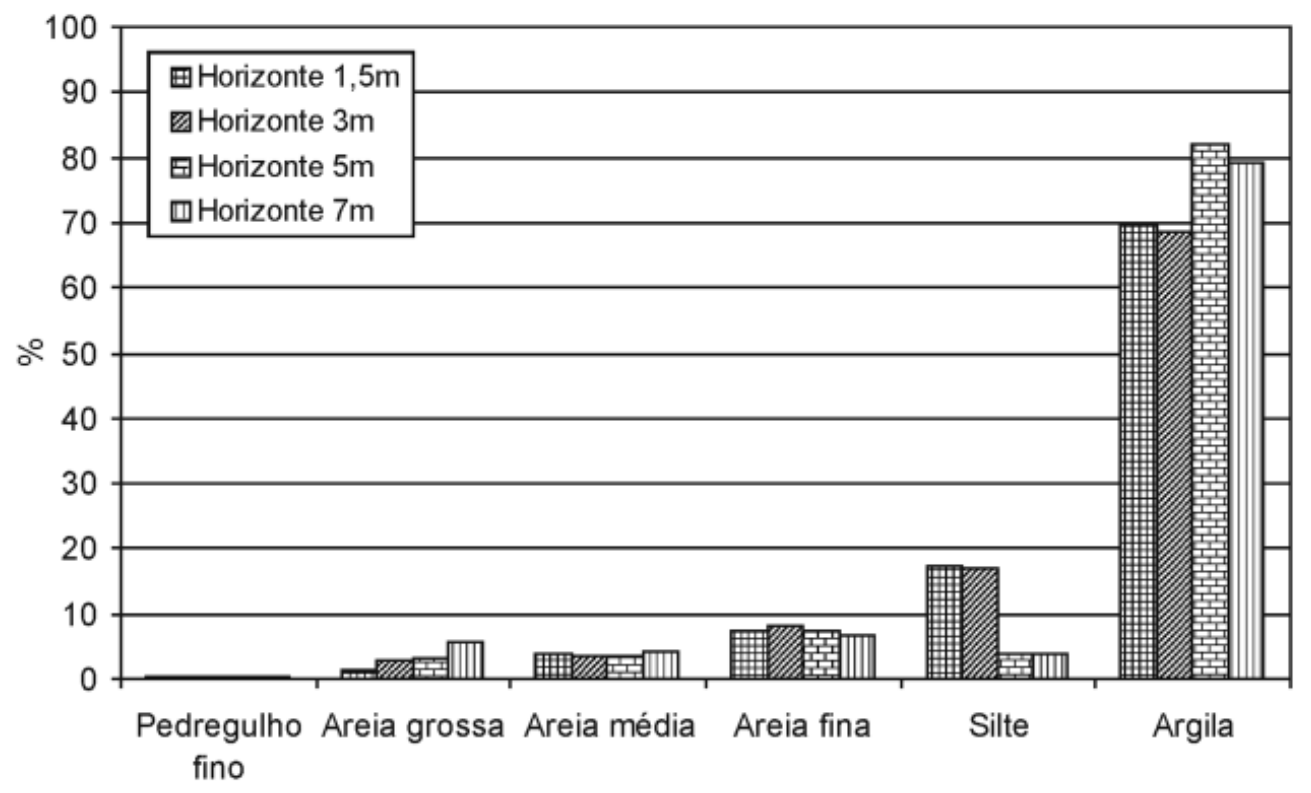

Figura 3 - Porcentagem granulométrica média por horizonte de solo.

em campo por meio do arranjo Schlumberger, com abertura máxima de $\mathrm{AB} / 2$ de $60 \mathrm{~m}$ e posicionamento do ponto central de leituras e dos eletrodos de potencial sobre as valas de resíduos.

Este arranjo consiste em pares de eletrodos dispostos em linha e referenciado a um ponto central de investigação, para transmissão de corrente elétrica, geração de campo elétrico em profundidade e posterior leitura por meio de pares de eletrodos de recepção (Orellana 1972). A disposição e movimentação dos pares de eletrodo em sentidos opostos a partir do ponto central de referência, permite leituras de resistividade elétrica para diversos níveis de profundidade, que resulta num gráfico de profundidade versus resistividade em 1D (Telford et al. 1990).

Foram realizadas 25 sondagens elétricas, subdivididas em três sondagens para as valas fechadas em $12 / 2001,12 / 2002,12 / 2003,12 / 2004,12 / 2005,12 / 2006$ e 12/2007, além de três sondagens realizadas em áreas externas ao aterro e a montante do fluxo d'água subterrânea, com o objetivo de determinar os valores naturais de resistividade para solo e rocha da área (Fig. 1).

Foi utilizado o resistivímetro Terrameter SAS 4000, fabricado pela ABEM (Suécia), com resolução de $1 \mathrm{mV}$, que consiste num módulo único de transmissão e recepção de dados, com $100 \mathrm{~W}$ de potência e quatro canais de leitura (ABEM 2006).

Este equipamento é calibrado para medidas de resistividade por meio de ciclos periódicos de corrente elétrica alternada e de baixa frequência, procedimento que permite a filtragem de ruídos do sinal adquirido. A razão V/I, ou seja, potencial (V) pela corrente (I) transmitida, permite leituras diretas de resistência elétrica em ohm $(\Omega)$. A resistência medida é multiplicada pelo fator $\mathrm{K}$, que representa o espaçamento dos eletrodos em superfície e resulta no parâmetro resistividade aparente ( $\rho)$ (equação 1):

$$
\rho=K \frac{\Delta \mathrm{V}}{\mathrm{I}} \quad \Omega . \mathrm{m}
$$

RESULTADOS Os dados de sondagem elétrica vertical foram tabelados e processados no programa IX1D, versão 3.24, desenvolvido pela Interpex.

Foi adotado o critério de camadas fixas para geração do modelo geoelétrico durante o processamento das sondagens, devido à presença de contatos bastante distintos entre camadas naturais e antropogênicas:

$1^{\circ}$ nível geoelétrico: solo de cobertura dos resíduos, com espessura entre 0,7 a $1 \mathrm{~m}$, definido a partir das perfurações via trado manual para coleta de solo. As menores espessuras foram descritas nas valas mais antigas, possivelmente devido à compactação do material.

$2^{\circ}$ nível geoelétrico: intervalo escavado e preenchido por resíduos, com espessura entre 4,2 e 4,6 m, variável devido à compactação dos resíduos.

$3^{\circ}$ nível geoelétrico: intervalo de solo entre a base das valas de resíduos e o topo da soleira de diabásio, com espessura de $5 \mathrm{~m}$.

$4^{\circ}$ nível geoelétrico: diabásio inalterado, parcialmente fraturado, exposto no talude da rodovia de acesso ao aterro, com espessura entre 8 e $10 \mathrm{~m}$.

$5^{\circ}$ nível geoelétrico: siltito, com início entre 18 e $20 \mathrm{~m}$ de profundidade.

Em termos gerais os resultados indicam um aumento constante de resistividade com a profundidade, exceto entre o $4^{\circ}$ e $5^{\circ}$ nível geoelétrico, onde ocorre o inverso. O cruzamento dos valores de resistividade com a idade das valas de resíduos investigadas individualmente, permitiu correlacionar variações temporais de resistividade elétrica (Fig. 4). 

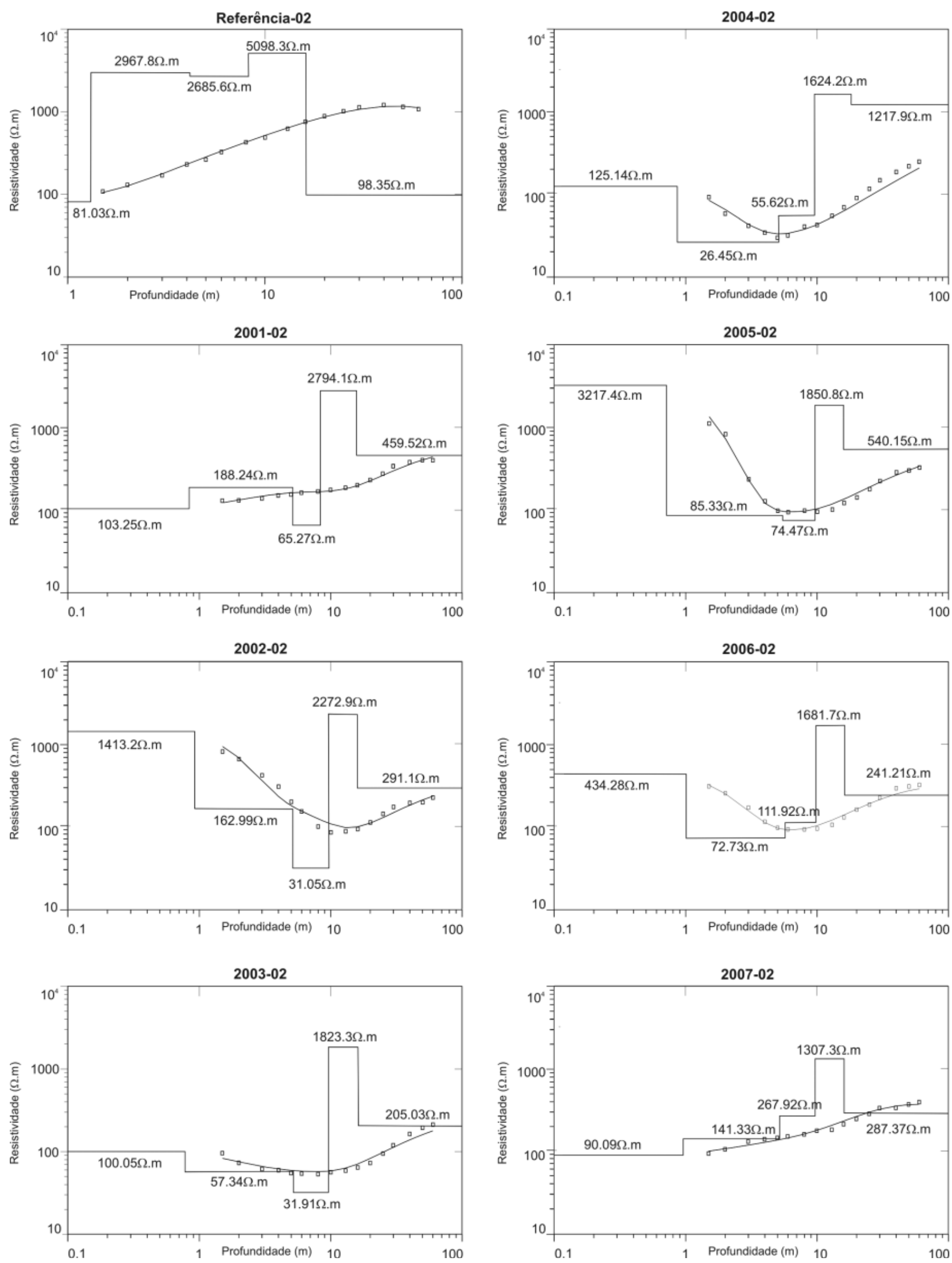

Figura 4 - Curva de campo, modelo e valores de resistividade para cada nível geoelétrico, referentes às SEVS 02 de cada conjunto medido. 
Em termos comparativos, os valores de referência são superiores às medidas sobre as valas. $\mathrm{O} 2^{\circ}$ nível geoelétrico apresenta queda nos valores de resistividade de 2007 a 2004, seguido por aumento até 2001. A análise do $3^{\circ}$ nível geoelétrico indica redução nos valores de resistividade de 2007 para 2003, estabilização em 2002 e suave aumento em 2001. A análise do $4^{\circ}$ nível geoelétrico indica tendência de aumento contínuo nos valores de resistividade das valas de 2007 para 2001, com suave redução nas medidas de 2004 e retomada da tendência de aumento para 2001.

Quando relacionado diretamente com teor de chorume, o padrão de queda de resistividade, entre 2007 e 2004 apresentado para o $2^{\circ}$ nível geoelétrico, é um indicativo de que houve aumento constante na produção de chorume no período, com variação de valores entre $144,33 \Omega . m$ e $26,45 \Omega . m$ respectivamente. O aumento constante da resistividade entre 2004 e 2001 indica um paulatino decréscimo na produção de chorume, com variação de valores entre $26,45 \Omega$.m para 2004 e $188,24 \Omega$.m para 2001. Também é possível afirmar que 2004 é o ano do ápice no consumo de matéria orgânica e consequente produção de chorume e que três anos foi o tempo necessário para concentração máxima de chorume no âmbito das valas de resíduos.

$\mathrm{O} 3^{\circ}$ nível geoelétrico corresponde à camada de solo abaixo das valas e em certo sentido reflete o padrão descrito acima, exceto pelo fato de que os valores mais baixos de resistividade, neste caso, foram medidos abaixo das valas fechadas em 2002, seguido por suave aumento nos valores de resistividade para 2001.

Os resíduos lançados nas valas não sofrem qualquer processo de compactação por trânsito de máquinas ou por sobrecarga de materiais, algo que torna este ambiente altamente permeável. Em contraste, o solo sotoposto apresenta baixa permeabilidade, conforme indicam os valores de condutividade hidráulica saturada próximo da superfície, mas correlacionáveis ao intervalo deste nível geoelétrico (entre 5 e $10 \mathrm{~m}$ ), com base nos elevados teores de argila obtidos por meio de peneiramento e análise granulométrica (Fig. 3).

A baixa permeabilidade deste horizonte deve ser o fator responsável pelo período de tempo relativamente maior para queda nos valores de resistividade, ou seja, $31,05 \Omega$.m para o $3^{\circ}$ nível geoelétrico em 2002 frente a $26,45 \Omega$.m para o $2^{\circ}$ nível geoelétrico para 2004 , ambos baseadas nas sondagens centrais para cada vala (Fig. 5).

Ainda deve ser considerada a possibilidade de trocas catiônicas em argilominerais, predominantemente cauliníticos e esmectíticos para solos de alteração de basaltos desenvolvidos e espessos, como no caso da área de estudo.

O quarto nível geoelétrico corresponde ao intervalo da soleira de diabásio e apresenta tendência constante de aumento nos valores de resistividade, embora haja uma pequena inflexão negativa para o ano de 2004 (Fig. 5). Esta queda de resistividade é correlacionável ao ápice de produção de chorume no horizonte das valas.

Aos valores integrados de resistividade para cada nível geoelétrico foram ajustadas curvas de tendência para fins estatísticos, ou seja, determinação de equações de reta de ajuste adequado, para cálculo posterior do tempo necessário para retorno aos valores naturais de resistividade para cada horizonte.

Para o $2^{\circ}$ nível geoelétrico foi possível o ajuste de curva de tendência por regressão polinomial de $3^{\mathrm{a}}$ ordem, com $\mathrm{R}^{2}$ de 0,89 (Fig. 6). $\mathrm{O}$ valor considerado como natural para este horizonte é de $466 \Omega . \mathrm{m}$ e corresponde a uma média dos valores obtidos para as sondagens elétricas de referência. Para este valor, são necessários cerca de 12 anos para retorno aos valores naturais de resistividade.

Este dado é bastante discutível, visto que o ato de escavação, abertura das valas e preenchimento por
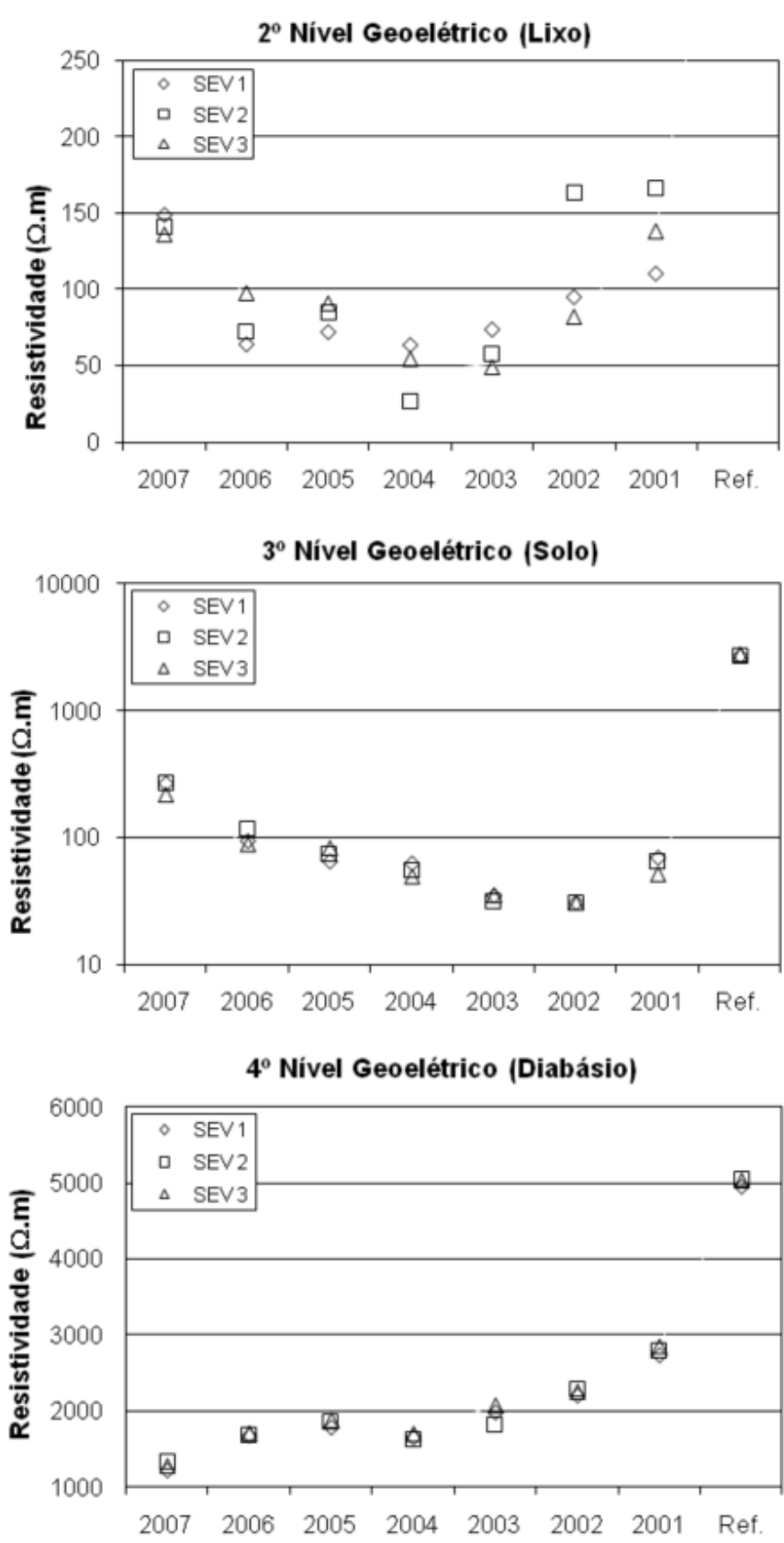

Figura 5 - Integração dos valores de resistividade por nivel geoelétrico. 

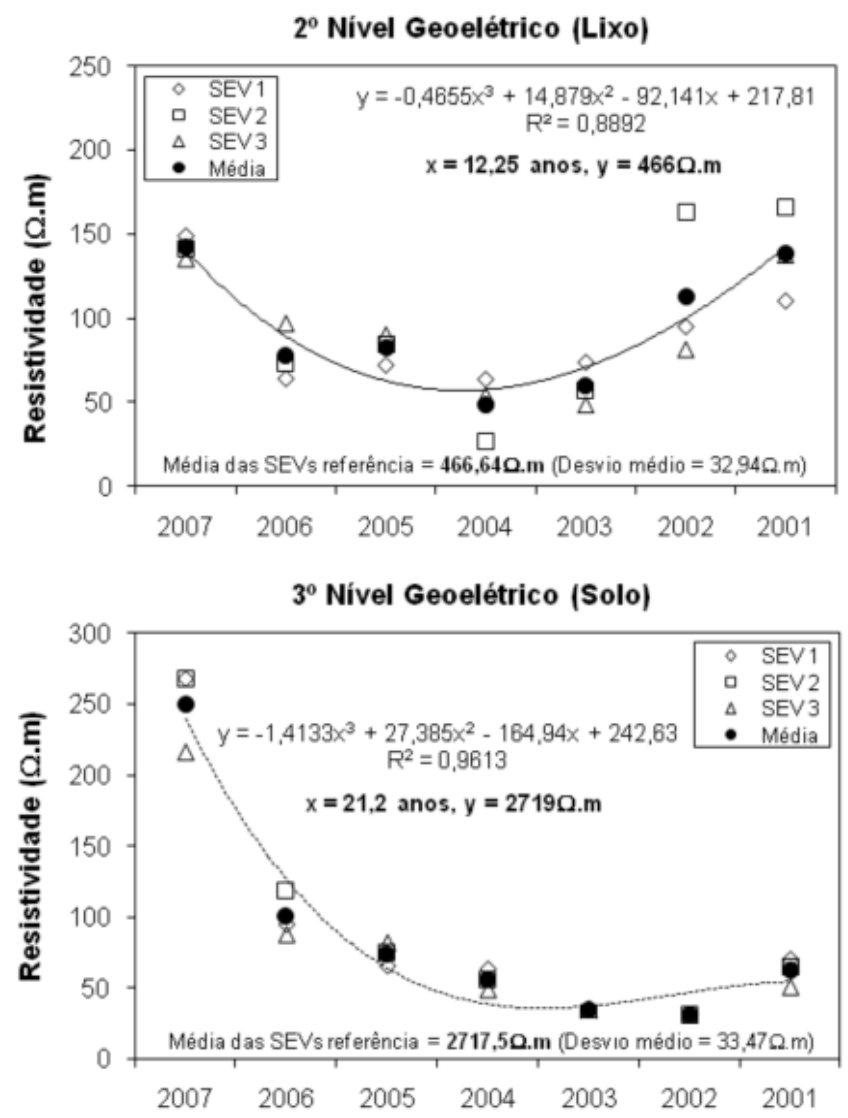

$4^{\circ}$ Nível Geoelétrico (Diabásio)

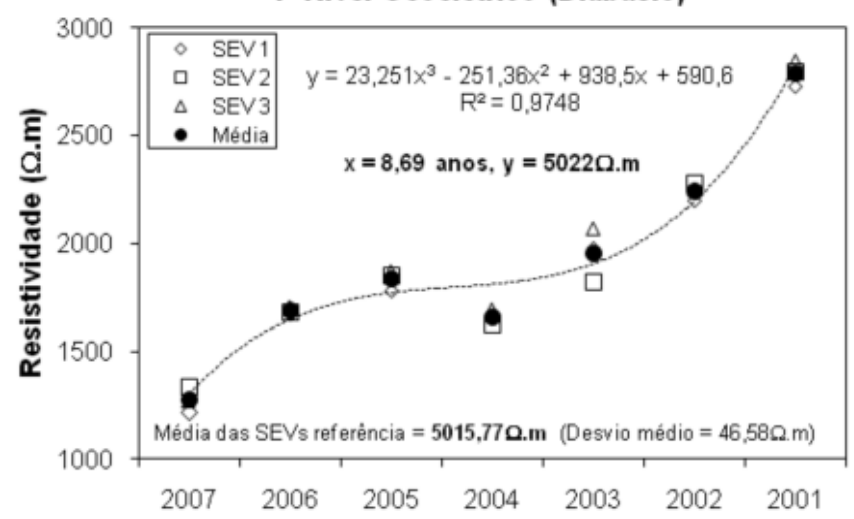

Figura 6 - Análise estatística dos dados por nível geoelétrico.

resíduos sólidos descaracterizam a área quanto às propriedades físicas e químicas em relação ao solo intocado de referência. O preenchimento por materiais antropogênicos como papéis e plásticos, distintos do solo argiloso natural da área, também inviabiliza quaisquer comparações.

Entretanto, tanto o solo sotoposto à base das valas quanto o intervalo da soleira de diabásio não sofreram escarificação ou quaisquer perturbações de ordem física, algo que permite comparações com o ambiente natural.

Para o $3^{\circ}$ nível geoelétrico foi possível o ajuste de curva de tendência por regressão polinomial de $3^{\mathrm{a}}$ ordem, com $R^{2}$ de 0,96 (Fig. 6). Neste caso, o valor considerado como referência foi de $2719 \Omega$.m e corresponde à média dos valores deste horizonte obtido nas três sondagens elétricas de referência. $O$ cálculo via equação de reta da referida curva indica ser necessários cerca de 21 anos para retorno aos valores naturais de resistividade.

Para o $4^{\circ}$ nível geoelétrico foi possível o ajuste de curva de tendência por regressão polinomial de $3^{\text {a }}$ ordem, com $\mathrm{R}^{2}$ de 0,97 (Fig. 6). Neste caso, o valor considerado como referência foi de $5022 \Omega$.m e também corresponde à média dos valores deste horizonte obtido nas três sondagens elétricas de referência. $\mathrm{O}$ cálculo via equação de reta da referida curva indica ser necessários cerca de 8 anos para retorno aos valores naturais de resistividade.

CONCLUSÕES Esta pesquisa demonstra a aplicabilidade da geofísica em estudos ambientais de monitoramento e de caráter previsional, essencialmente devido à possibilidade de aquisições de dados de forma multitemporal e contraste de propriedades físicas pertinentes e passíveis de medição pelo instrumental geofísico.

O caráter não invasivo desta ferramenta possibilitou a investigação indireta de horizontes de solo e rocha, abaixo de valas com resíduos e leitura do parâmetro físico resistividade elétrica, diretamente alterável em presença de chorume. Estudos semelhantes por meio de técnicas diretas de investigação, como sondagem e amostragem de solo e líquidos, ocasionam alterações significativas neste ambiente. Tais alterações consistem na abertura de caminhos preferenciais para percolação de chorume durante a perfuração para amostragem e que podem comprometer a credibilidade do dado resultante deste procedimento.

A análise estatística comparativa para o $2^{\circ}$ nível geoelétrico permite estimar cerca de 12 anos para retorno aos valores naturais de resistividade, embora seja um dado discutível e tecnicamente inadequado para fins de comparação com outras áreas.

O fluxo gravitacional do chorume, proveniente das valas de resíduos, permite uma relação direta entre alterações de resistividade no intervalo de solo e diabásio sotopostos e produção de chorume, algo que corrobora para a veracidade dos dados estimados.

Foi estimado cerca de 21 anos para que o intervalo de solo imediatamente abaixo das valas de resíduos retorne aos valores naturais de resistividade e cerca de 8 anos para retorno aos valores naturais para o intervalo da soleira de diabásio.

A estimativa de 21 anos revela o tempo máximo de produção e percolação de chorume de valas com $1.600 \mathrm{~m}^{3}$ de resíduos sólidos provenientes de domicílios de um município com cerca de 17.000 habitantes, num contexto de solo argiloso. É recomendada a continuidade dos estudos ao longo dos anos, para avaliação da veracidade e grau de precisão dos métodos, procedimentos e resultados alcançados no presente trabalho.

Ambas as estimativas são altamente relevantes para fins comparativos com aterros semelhantes quanto ao aspecto construtivo. A possibilidade de replicação metodológica desta pesquisa pode resultar em estudos 
voltados ao planejamento urbano e uso e ocupação do solo, no âmbito de planos diretores em aproximadamente 578 municípios paulistas que adotaram o sistema de destinação final de resíduos domiciliares por meio de aterros em vala, além de outros.
Agradecimentos Os autores agradecem ao técnico Francisco Manual Garcia Barrera, Leonardo Zani Castelo e André Passareli pelo auxílio na aquisição de dados em campo, além da Prefeitura Municipal de Cordeirópolis pela liberação para acesso à área do aterro.

\section{Referências}

ABEM - Geophysical and Vibration Monitoring Instruments. 2006. Terrameter SAS 4000/SAS 1000. Sundbyberg, ABEM Instrument AB, Instruction Manual, 136 p.

ABNT - Associação Brasileira De Normas Técnicas. 1989. NBR 10703: Degradação do Solo. Rio de Janeiro, ABNT, Normas Técnicas, $41 \mathrm{p}$.

Bagchi A. 1987. Natural attenuation mechanisms of landfill leachate and effects of various factors on the mechanism. Waste Management Research, 5:453-464.

Bell F.G. \& Jermy C.A. 1995. A seepage problem associated with an old landfill in the greater Durban area. In: Sarsby R.W. (ed.) Waste Disposal by Landfill - GREEN'93, Rotterdam, A.A. Balkema, p. 607-615.

Bennett P. \& Siegel D.I. 1987. Increased solubility of quartz in water due to complexing by organic compounds. Nature, 326:684-686.

Birks J. \& Eyles C.A. 1997. Leachate from landfill along the Niagara Escarpment. In: Eyles, N. (ed.) Environmental Geology of Urban Areas. St. John's, Geological Association of Canada, p. 347-363.

CETESB - Companhia de Tecnologia de Saneamento Ambiental. 2005. Inventário estadual de resíduos sólidos domiciliares. São Paulo, CETESB, Série Relatórios, 95 p.

Christensen T.H., Kjeldsen P., Albrechtsen H.J., Heron G., Nielsen P.H., Bjerg P.L., Holm P.E. 1994. Attenuation of landfill leachate pollutants in aquifers. Critical Review in Environmental Science and Technology, 24(2):119-202.

Fang H.Y. 1995. Bacteria and tree root attack on landfill liners. In. Sarsby R.W. (ed.) Waste Disposal Landfill GREEN'93. Rotterdam, A.A. Balkema, p. 419-426.

Farquhar G.J. 1989. Leachate: production and caracterization. Canadian Journal of Civil Engineering, 16:317-325.

Lago A.L., Elis V.R., Borges W.R., Penner G.C. 2009. Geophysical investigation using resistivity and GPR methods: a case study of a lubricant oil waste disposal area in the city of Ribeirão Preto, São Paulo, Brazil. Environmental Geology, 58:407-417.

Meju M.A. 2000. Geoelectrical investigation of old/ abandoned, covered landfill sites in urban areas: model development with a genetic diagnosis approach. Journal of Applied Geophysics, 44(1):115-150.

Mondelli G., Giacheti H.L., Boscov M.E.G., Elis V.R., Hamada J. 2007. Geoenvironmental Site Investigation using different tecniques in a Municipal Solid Waste Disposal Site in Brazil. Environmental Geology, 52:871-887.

Moreira C.A., Braga A.C.O., Fries M. 2009. Degradação de resíduos e alterações na resistividade elétrica, $\mathrm{pH}$ e Eh. Revista Brasileira de Geofísica, 27(2):283-293.

Moura H.P. \& Malagutti Filho W. 2003. Métodos de Eletrorresistividade e Polarização Induzida aplicados na área de disposição de resíduos urbanos: aterro controlado de Rio Claro, SP. Geociências, 22:129-139.

Orellana E. 1972. Prospeccion Geoelectrica en Corriente Continua. Madrid, Paraninfo, 523 p.

Santos A.A., Shiraiwa S., Silvino A.N.O., Silva W.T.P., Silva N.A., Silveira A., Migliorini R.B. 2009. Comparação entre investigação direta da água subterränea e radar de penetração no solo (GPR) na área do aterro sanitário de Cuiabá (MT). Revista Brasileira de Geociências, 39(4):768-722.

SMA - Secretaria do Meio Ambiente do Estado de São Paulo. 2005. Procedimentos para implantação de Aterro Sanitário em Vala. Disponível em http://www.ambiente. sp.gov.br/valas/proced_implantacao/proc_implant.pdf. Acessado em: 15/04/2011.

Telford W.M., Geldart L.P., Sheriff R.E. 1990. Applied Geophysics. 2.ed., New York, Cambridge University Press, $774 \mathrm{p}$.

Manuscrito ID 21281

Submetido em 16 de agosto de 2011 Aceito em 13 de outubro de 2011 